\section{MS20-P12 $\mathrm{I}_{7}{ }^{-}$: from stoichiometry to structural unit}

Alexander J. Blake ${ }^{1}$, Jeremiah P. Tidey ${ }^{1}$, Amy E. Lisle ${ }^{1}$, Martin Schröder ${ }^{1}$

1. The University of Nottingham

email: a.j.blake@nottingham.ac.uk

High pressure studies of metal coordination complexes have been reported for almost 30 years, but it is only recently these have appeared in significant numbers: in fact, of a total of around 50 studies, approximately two-thirds have appeared in the last five years [1]. One consequence of this limited number is that much of the coverage comprises isolated studies of very different materials and properties, with systematic comparative studies such as [2] being rare.

As part of a broader programme searching for new phenomena in metal coordination complexes, we turned our attention to the iodide salt of the complex cation $\left[\operatorname{Ag}\left([18] \text { ane } S_{6}\right)\right]^{+}$: this crystallises with the stoichiometry $\left[\operatorname{Ag}\left([18]\right.\right.$ ane $\left.\left.\mathrm{S}_{6}\right)\right] \mathrm{I}_{7}$ and adopts a highly unusual and visually striking structure (see Figure 1) whereby the cation templates the formation of a distorted cubic cage consisting of iodine molecules (I2) and iodide ions ( $\mathrm{I}^{-}$) with iodine-iodine separations of 2.7519(14) A for I-I and 3.3564(15) $\AA$ for I $\cdots$ I [3]. The iodines and iodides form an extended polymeric matrix in which the cations reside.

In response to compression to a maximum pressure of 46 kbar, $\left[\operatorname{Ag}\left([18] \operatorname{aneS}_{6}\right)\right] \mathrm{I}_{7}$ undergoes two distinct phase changes and increasing desymmetrisation of the cubic cage, the details and consequences of which will be explored.

\section{References:}

1. J. P. Tidey, H. L.S. Wong, M. Schröder \& A. J. Blake, "Structural Chemistry of Metal Coordination Complexes at High Pressure", Coord. Chem. Rev. 2014, 277-278, 187-207.

2. D. R. Allan, D. Bailey, N. Bird, A. J. Blake, N. R. Champness, D. Huang, C. P. Keane, J. McMaster, T. J. Prior, J. P. Tidey \& M. Schröder, "High pressure studies of six palladium and platinum thioether dihalide complexes", Acta Crystallogr., Sect. B 2014, 70, 469-486.

3. A. J. Blake, R. O. Gould, S. Parsons, C. Radek and M. Schröder, "Self-Assembly of Polyanions at a Metal Cation Template: Synthesis and Structures of $\left\{\left[\operatorname{Ag}\left([18] \text { aneS }_{6}\right)\right] \mathrm{I}_{7}\right\}_{n}$ and $\left[\operatorname{Ag}\left([18] \mathrm{aneS}_{6}\right)\right] \mathrm{I}_{3} "$, Angew. Chem. Int. Ed. Engl. 1995, 34, 2374-2376.

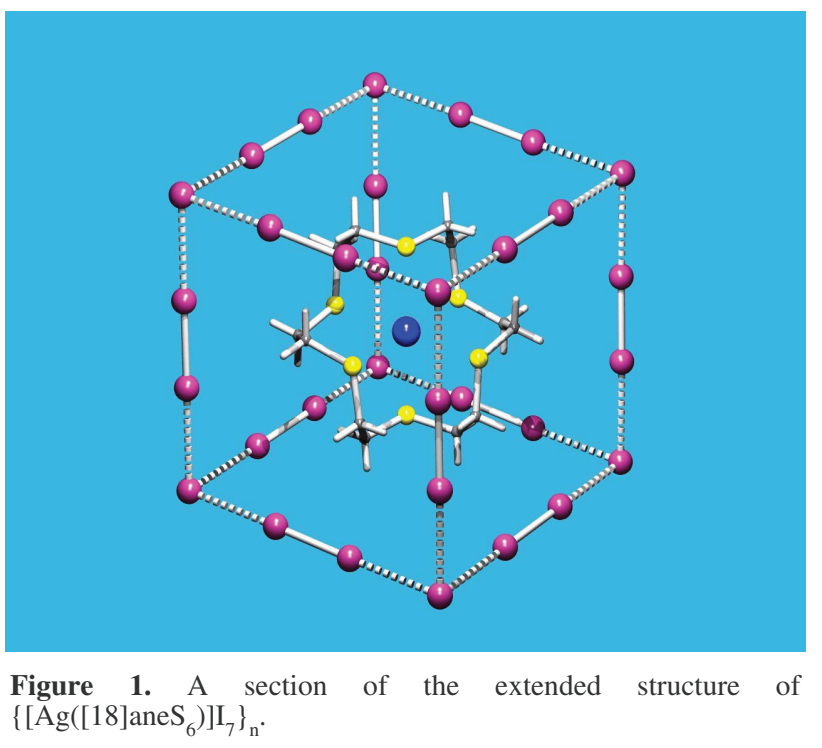

Keywords: high pressure, coordination complex, phase change, desymmetrisation, polyiodide 